\title{
SANDRA CINTO: MELANCOLIA DA PAISAGEM, MEMÓRIAS DO MAR
}

SANDRA CINTO: MELANCHOLY OF THE LANDSCAPE, MEMORIES OF THESEA

Luciane Ruschel Nascimento Garcez

UDESC

Resumo: Este artigo pretende discutir algumas questões do processo artístico da artista paulistana Sandra Cinto, a partir de obras apresentadas em duas exposições, onde o gesto do desenho e a história da arte se mostram presentes de forma poética e pungente. Pretende-se refletir sobre o processo artístico de Cinto como forma de problematizar questões como tempo, memória e história a partir da imagem.

Palavras-chave: Sandra Cinto, desenho, história da arte.

Abstract: This paper describes the practices of the São Paulo artist Sandra Cinto, from works presented in two exhibitions, where the drawing and the art history are present in a poetic and poignant way. It is intended to reflect on the artistic process of Cinto as a way of problematizing issues such as time, memory and history from the image.

Keywords: Sandra Cinto, drawing, art history. 
Este artigo pretende discutir algumas questões do processo artístico da artista paulistana Sandra Cinto, a partir de obras apresentadas em duas exposições: uma nos Estados Unidos e a outra na Espanha, onde o gesto do desenho e a história da arte se mostram presentes de forma poética e pungente. Cinto é escultora, desenhista, pintora, gravadora e professora, iniciou sua trajetória na década de 1990, e vem produzindo e expondo desde então. A artista trabalha com grandes instalações que remetem ao universo da paisagem, da música, da literatura, e sempre da história da arte, mesclando referências e trazendo o passado para o contemporâneo. O que marca nestes trabalhos selecionados para este estudo são os procedimentos por ela adotados; Sandra Cinto faz grandes desenhos, geralmente nas paredes, onde milhares de linhas vão tomando forma e criando movimento, para finalmente envolver o espectador na paisagem marinha, como que mergulhando realmente no universo da artista. São metáforas da água, do mar, das marinhas românticas os elementos que a artista utiliza para criar janelas no tempo, conduzindo o espectador a uma viagem pela história da arte, onde a melancolia da paisagem se faz presente em desenhos de grandes dimensões, recriando o movimento das ondas e a amplitude do céu, em uma imagem que transporta o espectador a um tempo remoto, a um Turner, por exemplo. Como cita a própria artista,

Eu tenho pensado muito na questão do tempo ligado ao espaço. Nas últimas instalações que eu realizei, tentei trabalhar essa questão de um deslocamento de tempo e espaço. É muito difícil, muito subjetivo, mas tenho uma vontade de sugerir para o observador uma experiência de deslocamento de uma realidade para outra. Uma das ferramentas que eu uso nesse sentido é trabalhar com a experiência da cor. Principalmente nas ins- talações monocromáticas, quando crio um ambiente todo de uma cor só [...] trata-se de um recurso para deslocar o observador para esse outro lugar (que não é o lugar do real, mas que é o lugar da memória...) (CINTO, IN:

CANTON, 2009, p. 47).

Questões que interessam pensar neste artigo são o tempo e a memória, e algumas questões relacionadas ao desenho e ao gesto de expandir este desenho. O desenho contemporâneo não se limita mais aos registros, esboços, ou estudos. Sendo definido como um processo de fazer marcas, o desenho na atualidade vai do monumental, ao micro. Desta forma a arte ativa o desenho como o vestígio de uma reflexão, de um pensamento, de um gesto.

O primeiro trabalho a ser abordado é uma instalação na exposição Encontro das Águas, no Seattle Art Museum, em Seattle, Estados Unidos, que aconteceu de abril de 2012 a maio de 2013, concebida especialmente para o espaço arquitetônico do Olympic Sculpture Park Pavillion. Foi a primeira vez que um artista brasileiro fez uma exposição no SAM, considerado um museu importante da Costa Oeste Americana, uma oportunidade de visibilidade para a arte contemporânea brasileira. Este espaço abriga obras permanentes de artistas como Louise Bourgeois, Alexander Calder, Richard Serra, Claes Oldenburg e Mark Dion, entre outros, o que prefigura sua importância na arte contemporânea.

Nesta mostra a artista faz o desenho de um mar tempestuoso em escala monumental nas paredes interna e externa do pavilhão, ocupando a parede toda, e coloca um barco/escultura de madeira em escala real no interior do espaço expositivo, em frente ao desenho, o que sugere ao observador a condição de um náufrago à deriva (ver figuras 1 e 2).

Para fazer esta instalação, a artista pintou a parede do pavilhão em quatro tons de azul, sen- 


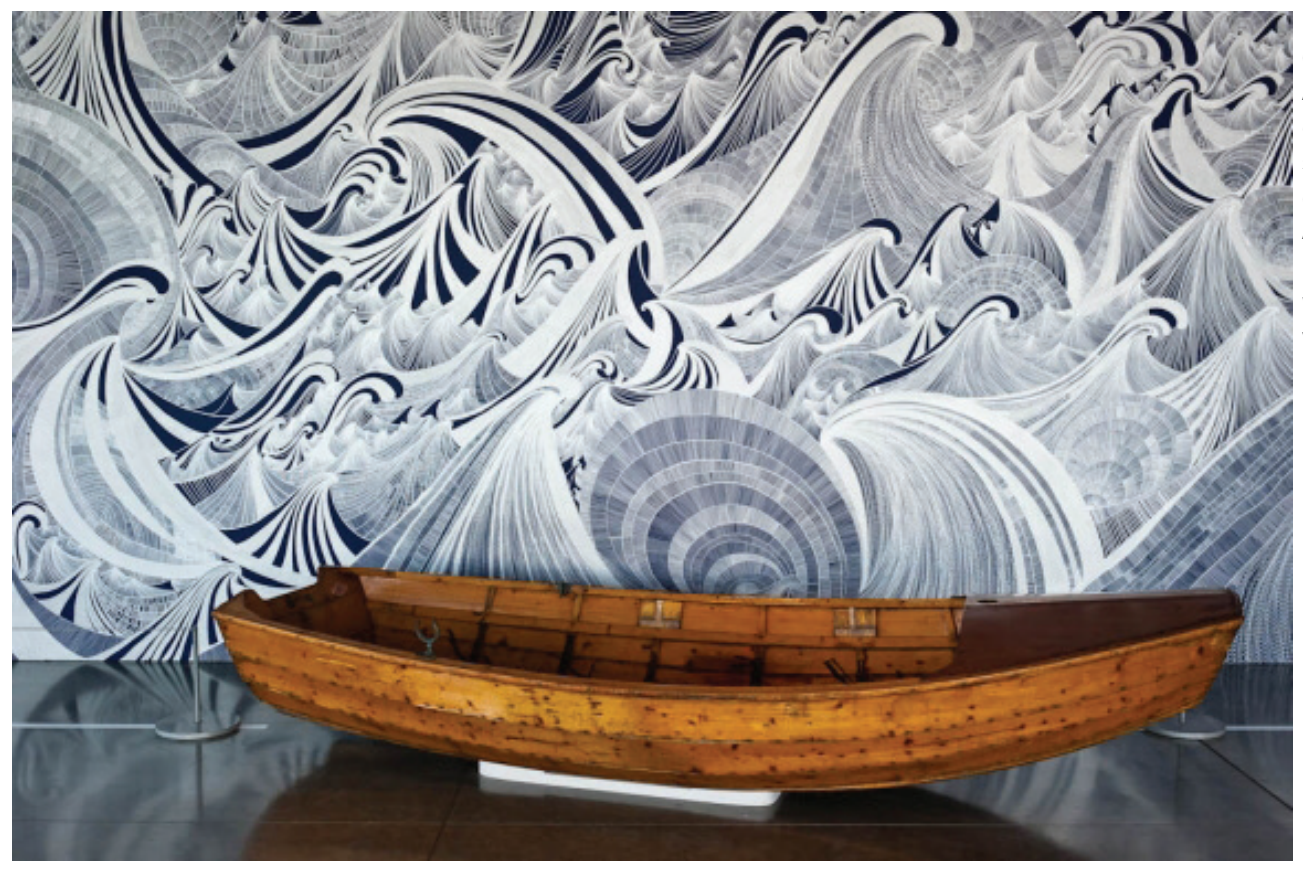

Figura 1 - Sandra Cinto. Encontro das Águas. Desenho com caneta permanente sobre a parede, barco de madeira. Seattle Art Museum. Fonte da imagem: http://www. woonschrift.nl/lijntjesvan-sandra-cinto/

do que o mais escuro ocupa aproximadamente 70\% da parede, partindo do plano inferior, e o mais claro está no alto, dentro da gramatura é a linha mais discreta. Por cima ela rascunha o movimento das ondas e a direção que estas devem tomar, a partir desta delimitação de espaço, as ondas vão ganhando vida conforme a artista - e assistentes que a acompanham na empreitada, mais os vários voluntários que se dispõem a trabalhar junto - começa a preencher estas formas com linhas repetitivas, algumas mais espessas, outras mais finas, dependendo do momento são linhas pontilhadas, na sua maioria linhas cheias, nas mais variadas direções, dependendo do movimento da onda. Este procedimento, de brincar com as linhas, é o que garante movimento ao desenho, trazendo a sensação das ondas quebrando.

Nesta instalação o mar está tão agitado que passa a impressão de uma tempestade, com várias ondas se sobrepondo. A artista trabalhou com caneta permanente branca, desta forma o contraste com o azul profundo do fundo da parede é bem grande, e em alguns momentos as linhas quase fecham a forma da onda, gerando uma impressão de espuma. A maneira como a artista organiza suas linhas e a forma que ela confere às ondas lembram as gravuras orientais, com pontas curvas e delicadas, onde a base das ondas é larga e o cume que se fecha estreito, como triângulos, em que certos momentos remetem à arquitetura japonesa.

Influenciada por artistas como Sol Le Witt, Regina Silveira e Katsushika Hokusai, a artista compõe as paisagens direto sobre a parede. Regina Silveira é uma das artistas brasileiras contemporâneas que figuram na lista de artistas que compõem com o espaço expositivo, cada instalação é pensada isoladamente, ou reorganizada para dialogar com o espaço onde se insere. Assim como Sandra Cinto, Silveira compõe obras 'limpas', sofisticadas no sentido do acabamento, ambas configuram o gesto de 'dar vida' ao espaço da instalação. 
Figura 2 - Katsushika Hokusai. The Big Wave (1829-32). Gravura. Fonte da imagem: http:// en.wikipedia.org/ wiki/The_Great_Wave_off_Kanagawa\#mediaviewer/ File:Great_Wave_off_ Kanagawa2.jpg

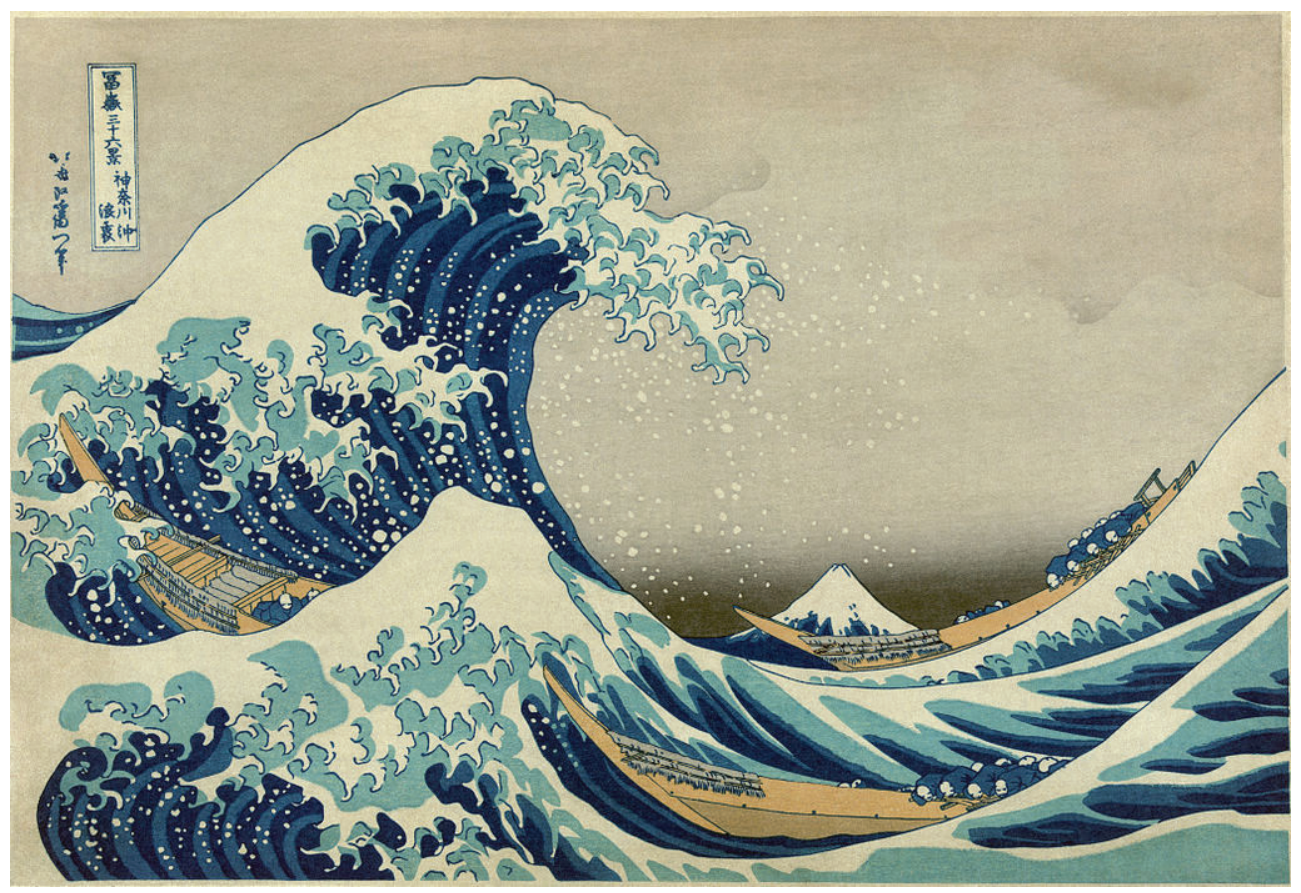

Hokusai - artista japonês do início do século XIX - é uma referência frequentemente levantada por Cinto, com sua gravura intitulada "The Big Wave” (1829-32), que representa uma enorme onda ameaçando alguns barcos (ver figura 2) ${ }^{1}$. Nesta referência percebe-se a linearidade de Cinto em paralelo com a gravura japonesa. A artista demarca suas ondas de maneira similar às ondas de Hokusai, as linhas que dão forma à base da onda, quando esta está se formando. $\mathrm{Na}$ artista brasileira, entretanto, as ondas se quebram e se formam em direções variadas, na gravura japonesa as ondas estão orientadas da esquerda para a direita, o mar de Cinto é revolto, e o mar de Hokusai é mais ameaçador, com suas ondas na iminência de quebrar por sobre os barcos.

Em Le Witt², outro artista mencionado por

1 Em entrevista disponível no site: http://arteref.com/instalacao/mural-de-sandra-cinto-no-seattle-art-museum/

2 LeWitt, S. (1967) "Paragraphs in Conceptual Art”, in Artfo-
Sandra Cinto, percebe-se que talvez sua fala esteja alinhada ao pensamento deste artista, quando este comenta que esboços e esquemas podem ser considerados trabalhos. Em Sandra Cinto e seus desenhos nas paredes podem-se pensar em projetos e esquemas, uma vez que a artista esquematiza suas ondas, completa os desenhos com as linhas, como um esboço. E este é o seu trabalho final, enquanto durar a exposição.

Em frente a este mar tempestuoso, a artista colocou um pequeno barco de madeira clara, com aspecto antigo. Como se estivesse a navegar por entre as ondas, a exemplo dos barcos na gravura de Hokusai (ver figura 2). Dentro ela desenhou com caneta permanente azul escuro a imagem de um desenho encontrado da balsa construída pelos náufragos a partir dos destroços da fragata da Medusa em 1816 (ver figura 3),

rum 5, no. 10, pp. 79-83, June 1967. 
fato representado por Theodoré Gericault em seu famoso quadro, Balsa da Medusa ${ }^{3}$ (ver figura 4), o qual a artista cita como uma referência muito constante em suas representações de mares revoltos. A referência à história da arte é direta e literal pela artista, que não se furta a comentar esta imagem que a acompanha há tempos. Mas para acessar esta informação, o espectador tem que se aproximar e olhar dentro do barco, estar imerso na experiência. Este movimento de certo modo coloca o espectador 'dentro' da cena, como se ele fizesse parte desta paisagem, e estivesse à deriva neste pequeno barco. O público não fica mais à distância, neste pequeno detalhe, a artista convida seu espectador a navegar com ela.

Esta sensação de o espectador se encontrar em meio a esta turbulenta paisagem se passa porque o mar desenhado pela artista não tem início nem fim, seu desenho já posiciona o público no 'meio' deste oceano de ondas. Não se veem horizontes, não se vê areia, nem barcos desenhados, somente as ondas, e o barquinho de madeira em frente a esta paisagem. Ao se colocar 'diante' da parede, a sensação é de estar 'dentro' do desenho. Este deslocamento pode ser pensado como um mergulho em outras temporalidades, estar diante das paisagens românticas, das marinhas, evocando uma memória onde o mar significava o mistério, a travessia. Questões evocadas no Romantismo.

Cinto diz que vem há muitos anos usando a imagem desta pintura de Géricault, devido também a seu conteúdo político, ela usa essa imagem como uma metáfora ao contexto político contemporâneo. A pintura foi inspirada no

3 (Le Radeau de la Méduse, 491 X $716 \mathrm{~cm}$ ) é uma pintura a óleo de 1818-1819 feita pelo pin-tor e litógrafo da época do Romantismo, Théodore Géricault (1791-1824). Está exposta no Museu do Louvre, Paris.

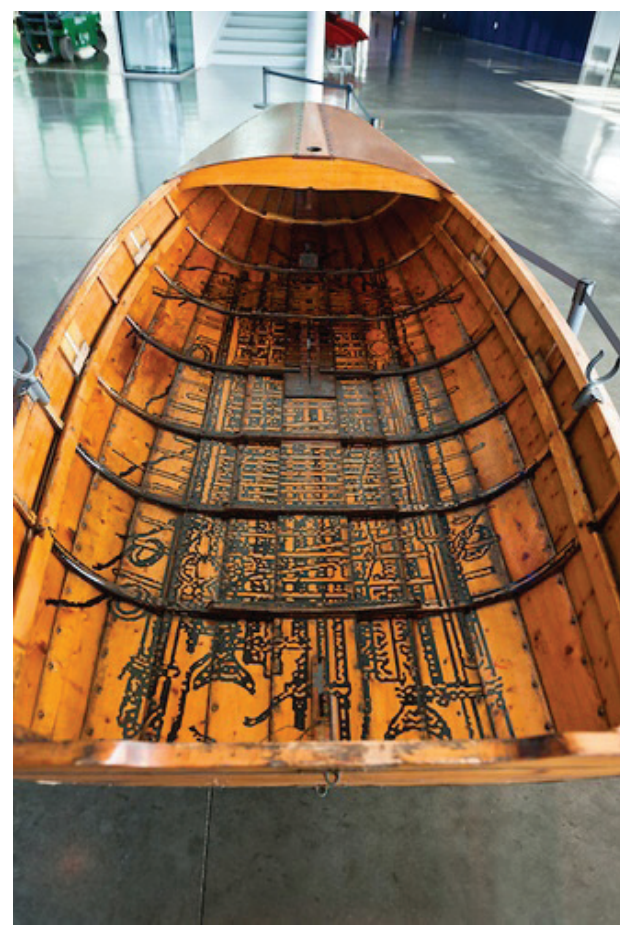
Figura 3 - Sandra Cinto. Encontro das Águas. Desenho com caneta sobre o barco. Seattle Art Museum. Fonte da imagem: http://rw.photoshelter. com/gallery-image/ Sandra-Cinto-Olympic-Sculpture-Park/ G00006exoFRuhhxw/ I0000qsTXXpolHeQ/ C0000pxsT3P6pK6o

naufrágio da fragata Medusa, em 1816, que ia da França para o Senegal. O navio transportava cerca de 400 pessoas, entre elas o futuro governador do Senegal. Depois do naufrágio, 147 pessoas não conseguiram lugares nos botes salva-vidas e, por isso, se amontoaram em uma pequena jangada construída com tábuas, cordas e partes do mastro. A embarcação foi nomeada "A Balsa da Medusa", em referência ao próprio navio naufragado. Após diversos dias na embarcação um dos sobreviventes, o médico Jean -Baptiste Henry Savigny, assumiu a liderança do grupo e passou a dissecar os corpos dos mortos para que servisse de alimento aos sobreviventes, para que estes não morressem de fome. Depois de 13 dias à deriva a Balsa da Medusa foi resgatada pelo Argus, um pequeno navio mercante. A esta altura apenas 15 sobreviventes restaram. Este fato se tornou extremamente polêmico à época, foi um escândalo, onde o capitão teve que responder na corte marcial, o 
Figura 4 - Théodore Géricault - A Balsa da Medusa (1818-19). Dimensões: $491 \mathrm{X}$ $716 \mathrm{~cm}$. Museu do Louvre, Paris. Fonte da imagem: http://dereksarthistorytimeline. weebly.com

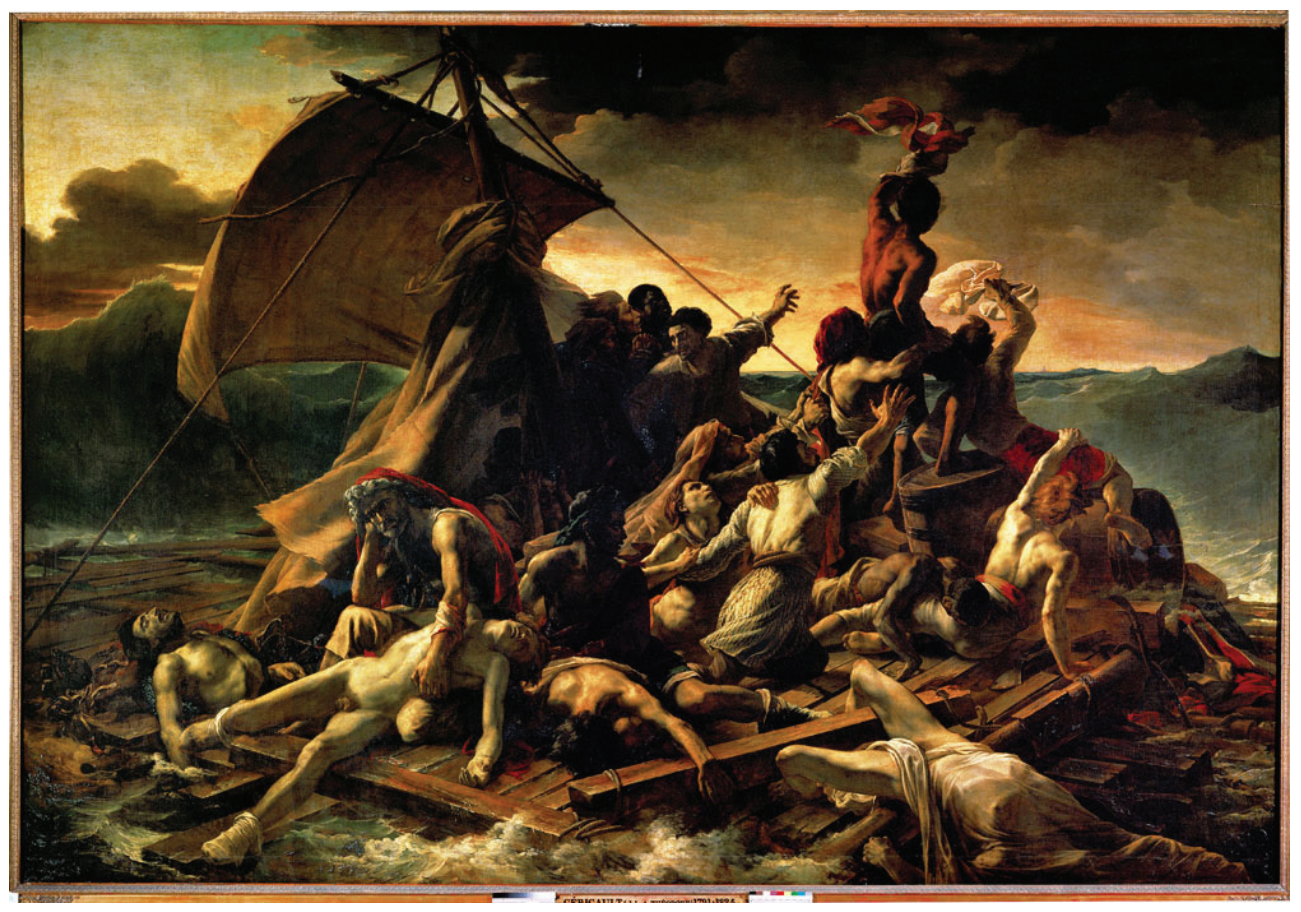

fato foi brilhantemente representado pelo pintor. Géricault propôs-se contar a tragédia pelo ponto de vista de dois sobreviventes, que estão representados ao pé do mastro, e que puderam fornecer uma descrição acurada da jangada.

A segunda exposição de Sandra Cinto que será explorada neste artigo é "A Outra Margem" (La otra orilla), no Centro Atlántico de Arte Moderno de Las Palmas de Gran Canaria, CAAM, ilhas Canárias, Espanha, que aconteceu de junho a setembro de 2014. São peças produzidas especificamente para o CAAM refletindo as vertentes principais de seu trabalho: pintura, escultura, desenho e instalação site-specific. Nesta exposição, quando Ihe foi enviada planta do museu, ela viu que um dos locais mais importantes era a biblioteca, desta forma sua proposta passou a transitar por esta noção, da leitura, do livro, aprendizagem, trocas, cultura, aquilo que permeia a noção de biblioteca e flutua no imaginário de todos ao se mencionar este espa- ço de produção de conhecimento.

A artista pensou três instalações distintas, mas conectadas entre $\mathrm{si}^{4}$. A primeira delas intitulada 'Pausa', onde ela trabalhou com suas duas assistentes brasileiras, desenhando na parede um pentagrama mudo, colocando 11 instrumentos musicais de corda - violinos, violoncelos, contrabaixos - transformados (ver figura 5). O pentagrama, que é a estrutura para a música, neste trabalho se tornou a estrutura da instalação, base de toda a montagem, pois toda a proposta parte do desenho deste, que foi modificado pela artista. Cinto fez um estudo sobre as linhas e modificou a distância e a sequência de repetição entre elas, remetendo as linhas à paisagem e também ao movimento das ondas. E tornou-o mudo, pois a artista desenha só as linhas, e quando este não apresenta as

4 Conforme entrevista disponível em: http://www.caam. net/es/140612scinto_v.htm, com acesso em 28 de setembro de 2014 . 


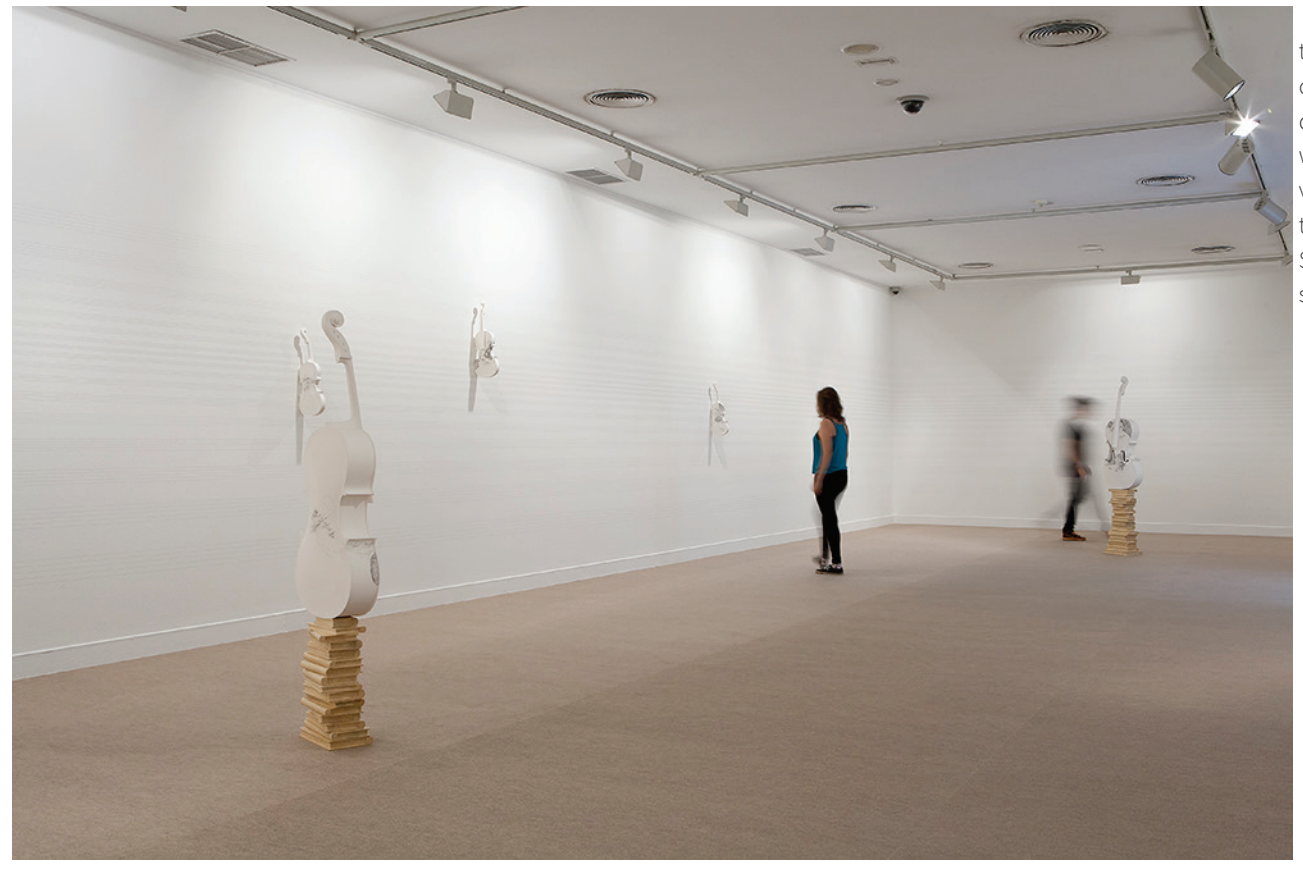

Figura 5 - Sandra Cinto, Pausa, 2014. Foto: cortesia CAAM. Fonte da imagem: http:// www.m-arteyculturavisual.com/wp-content/uploads/2014/09/ Sandra-Cinto-Pausa-2014.jpg

notas musicais, ele se mostra enquanto 'pausa', 'silêncio'. Os instrumentos aparecem colocados na parede, alinhados ao pentagrama, a título de notas musicais. Os instrumentos são silenciados também, pois têm sua estrutura modificada e não podem ser tocados. Os instrumentos são desprovidos das aberturas que propagam o som e são tiradas as cordas que os fazem tocar. São pintados de branco e sobre eles são desenhadas paisagens, da mesma forma que nos murais, paisagens feitas através de linhas curvas, orgânicas, repetidas, formando espaços de paisagens, montanhas, cachoeiras, mares, rios, feitos com caneta permanente preta bem fininha. Onde o desenho da parede é a parte racional da instalação, linhas retas, distribuídas matematicamente, e o desenho dos instrumentos seriam a parte orgânica, como se os desenhos figurassem a música que sairia dos instrumentos. A artista tenta criar uma certa 'sonoridade' no desenho ${ }^{5}$, pela organicidade e repetição das linhas. A ideia de montagem ao distribuir os instrumentos na sala era de criar uma sala de concertos. Alguns deles estão instalados no chão, sobre pilhas de livros talhados em madeira.

A ideia da artista era propor ao visitante um espaço de silêncio, uma pausa mesmo, mas também um espaço de reflexão, colocando em discussão o espaço contemporâneo do caos e do barulho, poluição sonora dos grandes centros, e o ritmo desenfreado que faz com que as pessoas não se deem mais o devido tempo. O pentagrama vazio funciona como uma marcação de tempo, como se fosse uma partitura do silêncio, onde cada instrumento colocado contasse o tempo da pausa, de se calar. A ideia da instalação era falar sobre 'tempo, espaço e silêncio'.

Na segunda instalação, a artista tentou criar

5 Em entrevista disponível em: http://arte1.band.uol.com. br/paisagem-silenciosa/ 
Figura 6 - Sandra Cinto, A outra margem 2014. Foto: cortesia CAAM. Fonte da imagem: https://c2.staticflickr.com/

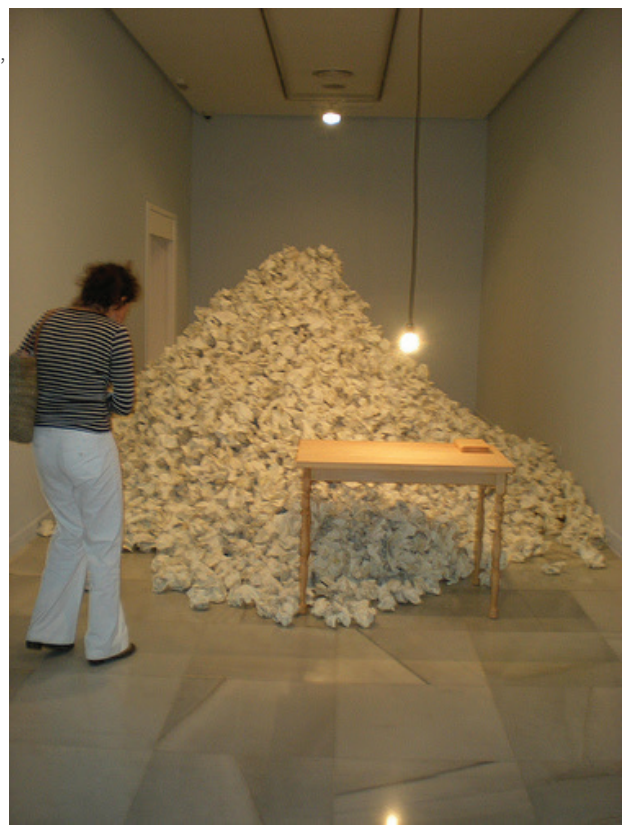

um espaço, uma ideia de uma habitação, uma ficção, insinuando um local onde uma pessoa tivesse estado por muito tempo, vários dias, na tentativa de criar o desenho perfeito, o que nunca consegue. Nesta 'habitação', uma sala também pintada de azul, ela amontoa papeis brancos amassados, vestígios das tentativas de criação que não foram alcançadas, a ponto de tomar conta de toda sala e escapar pela porta, como que 'escorrendo', de certo modo referenciando ainda à água, ao mar (ver figura 6). Em frente aos papeis está uma mesa de madeira clara e uma lâmpada pendurada em cima, representando o espaço para desenhar, espaço de criação. Em cima da mesa, um livro de madeira, mais uma vez ela remonta ao espaço de conhecimento, e 'cala' este conhecimento ao oferecer um livro de madeira que não abre, é uma escultura fixa, impossivel de ser lido. Os amontoados de papel estão ali devido à impossibilidade de alcançar a criação perfeita. Como se amontoam sonhos pela impossibilidade de realizá-los ao longo da vida. O papel que a artis- ta usa na instalação não é o do suporte do desenho, são papeis em branco amassados pela impossibilidade de realizar o desenho, este está na parede, em outra 'habitação', uma ironia da artista talvez, ou poesia de pensar a expansão do desenho, de pensar que o material ideal para o desenho perfeito é o material disponível: a parede. E aquele que cria o faz onde estiver e com o suporte que puder, não existe o espaço perfeito da criação, nem a situação perfeita para tal.

$\mathrm{Na}$ terceira instalação, ela mescla desenho, pintura e instalação. Em frente ao painel desenhado está um banco de madeira clara, cujos pés são livros (ver figuras 7 e 8), metáfora onde o que confere equilíbrio ao assento é a base da cultura. O mar revolto, desenhado na parede mais uma vez, está conectado ao mar de Géricault e a Balsa da Medusa, referenciado pela artista (em entrevista ${ }^{6}$ ), onde mais uma vez ela traça um paralelo entre a tragédia da balsa com a tragédia contemporânea. São três instalações distintas, pensadas especialmente para a planta do CAAM, conectadas entre si pelos desenhos nos corredores.

Nestas duas exposições - nos EUA e na Espanha - têm-se várias instâncias que podem ser pensadas: como o silêncio, proposta na instalação "Pausa", mas também na instalação em Seattle, com o barco que convida à deriva e coloca o público em um estado imaginário de navegação, sozinho em meio ao oceano; como os objetos 'conhecidos', como os livros, mesas, barcos. Tem-se também a memória, ao atravessar temporalidades interagindo com a história da arte, remetendo diretamente a Géricault, mas também às paisagens marinhas do Romantismo, a melancolia das navegações, onde nunca se sabia se o ente querido voltaria daquele

6 Em entrevista disponivel em http://www.caam.net/ es/140612scinto_v.htm, com acesso em 28 de setembro de 2014. 

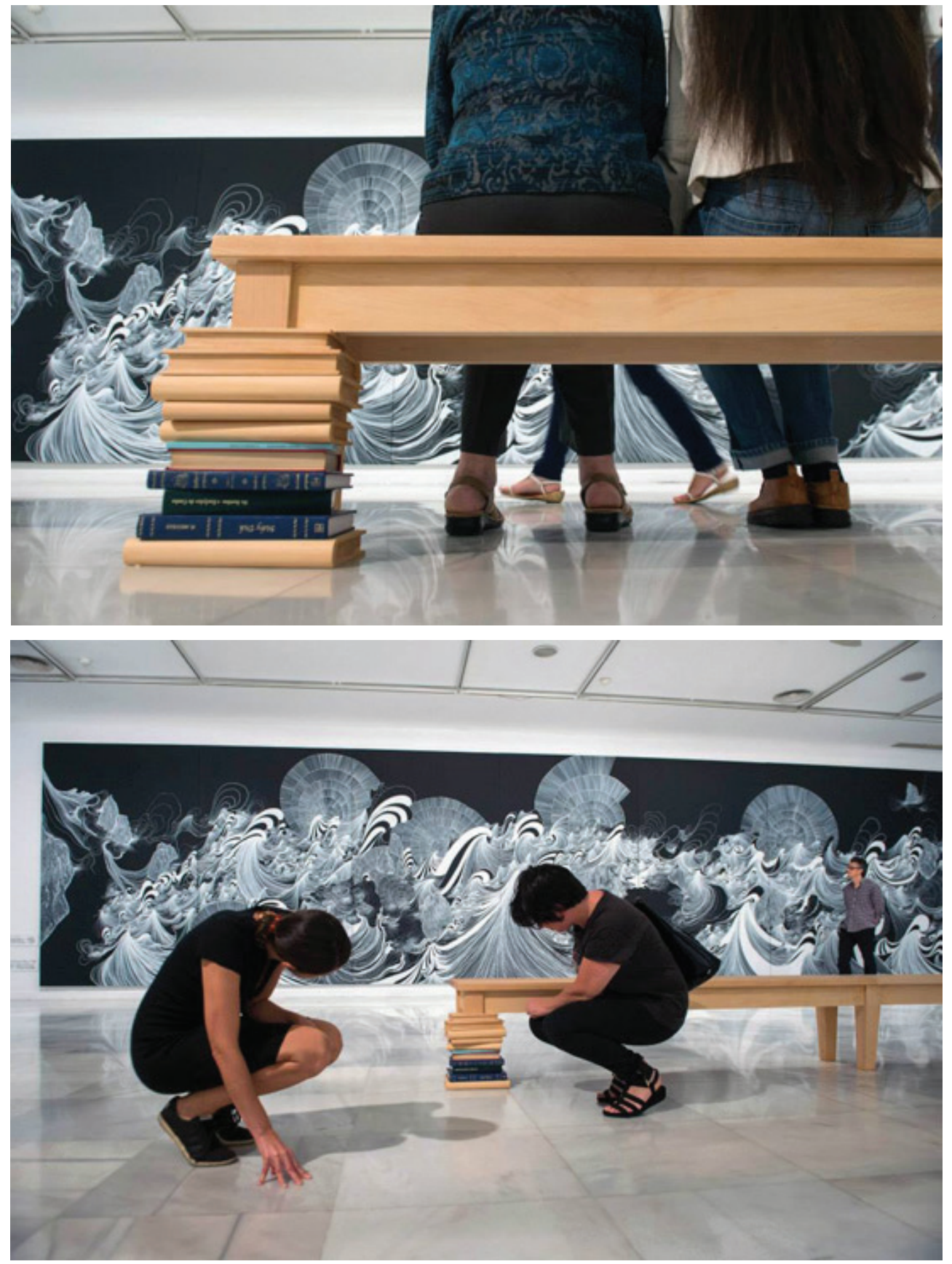

Figura 8 - Sandra Cinto. A Outra Margem. Centro Atlântico de Arte Moderna -CAAM, Ilhas Canárias, Espanha, 2014. Fonte da imagem: http://www.caam.net/es/140614_galeria_inaug.htm
Figura 9 - Sandra Cinto. A Outra Margem. Centro Atlântico de Arte Moderna -CAAM, Ilhas Canárias, Espanha, 2014. Fonte da imagem: http://www.caam.net/es/140614_galeria_inaug. htm 
mar imenso e misterioso; o tempo, tempo da exposição, onde os desenhos e pinturas são literalmente apagados quando estas terminam, o tempo da fatura. E também suas instalações interrogam o estatuto do desenho no contemporâneo, onde o gesto de ampliar sua ação se torna o trabalho final.

Os valores românticos dos séculos XVIII e XIX consideraram o desenho como o meio ideal de expressão do descontentamento dos artistas com o mundo em que viviam. O desenho seria a possibilidade de criação de um mundo imaginário, um local onde as normas estabelecidas na sociedade em vigor poderiam ser alteradas, devido ao imediatismo da criação ligado a esta técnica, o que traria a contraposição imediata ao descontentamento. Pode-se pensar o desenho como gesto, pensamento, sistema de relações e ideias, não se limitando a projeto, ou esboço, o desenho no contemporâneo se libertou, ampliou seu campo para o tridimensional, se legitimando como obra.

Nas obras vistas o desenho se configura como um ato espontâneo, coletivo e imediato. Características que anteriormente afastavam o desenho do público - que só teria acesso à obra final - e o colocavam no estatuto de projeto. Arte como ideia e como gesto são duas fontes associadas à desmaterialização do objeto, no gesto a matéria transformou-se em ação, gestualidade, movimento. Mesmo nos desenhos de Sandra Cinto sente-se esta desmaterialização, uma vez que são efêmeros. E sua gestualidade é ressignificada na coletividade da ação de desenhar. A artista trabalha com novos modelos de desenhar.

À Sandra Cinto interessa pensar o processo do criador, do artista, que tenta fazer algo, engaja em um projeto, esta seria uma homenagem a este momento de criação. Ela cita a folha de papel em branco ${ }^{7}$ na instalação na Espanha, considerada pesadelo para alguns, a exemplo da tela em branco também, este espaço cheio de criação, à espera de ser descoberto e desenvolvido, mas que exige o primeiro passo. Ao mesmo tempo a folha/tela em branco é a imagem do início da obra, algo que está prestes a se desvelar, um momento de muitas possibilidades, muitos caminhos. Para a artista a folha em branco seria uma imagem de beleza e potência.

Em 'Pausa' o silêncio vem como uma forma de se opor ao ritmo contemporâneo e à invasão dos ruídos. A pausa a que a artista se refere e que intitula a instalação remete também ao que muitos procuram no mar, uma pausa para o cotidiano, o barulho da cidade substituído pelo marulho, pausa esta que costuma ser um respiro na rotina dos que podem se dar a este luxo de 'correr para o mar' quando o resto está demais.

David Barro, curador da mostra, comenta que:

o silêncio é agora uma espécie de imagem abismal, precipício onde o tempo para. Uma série de instrumentos musicais de cordas estão, paradoxalmente, mudos esse produz um despojamento cromático em relação às outras salas. Como nas outras salas, convertidas em atmosferas, não percebemos fronteiras nem perspectivas, e o espectador se vê envolto em um mundo belo que esconde, no entanto, uma angústia existencial combativa contra problemas e desigualdade social. É assim que a obra de Sandra Cinto se conjuga político, incidindo na dificuldade da travessia, da vida. Sua última paisagem é um pentagrama, onde escreve o espaço e o tempo, mas também os silêncios, os vazios ... da outra margem. ${ }^{8}$

\footnotetext{
7 Em entrevista disponível em http://www.caam.net/ es/140612scinto_v.htm, com acesso em 28 de setembro de 2014.

8 "el silencio es ahora una suerte de precipicio, de imagen abismal donde el tiempo se detiene. Una serie de instrumentos musicales de cuerda están paradójicamente mudos y se produce un despojamiento cromático con respecto
} 
A questão do conhecimento, levantada pela artista com a referência aos livros, é explorada em outros trabalhos da artista, talvez pelo fato de ela ser também professora, o lado teórico, da pesquisa e da propagação do conhecimento, também se mostra importante em seu processo. Em uma entrevista a Katia Canton, ela diz:

Os livros também são objetos imensamente preciosos, transmitem a cultura, o saber, as histórias, de geração para geração. E faço mesmo uma homenagem à literatura, pois as minhas influências não vêm só da arte, vêm da dança, da literatura, da música. Trabalho com livros neste sentido, pois nós somos feitos dos livros que lemos. [...] Esses objetos são símbolos de memória... [...] (CINTO, IN: CANTON, 2009, p. 49-50).

A artista problematiza também a memória em seus trabalhos, evocando outras temporalidades, que ela mesmo referencia, mas também trabalha na memória pessoal, ao trabalhar com objetos, e aí se encaixa o livro, que fazem parte da vida de muita gente, em muitas culturas, desta forma a artista consegue tocar a um público amplo e diversificado.

Como ela mesma diz,

Eu busco uma linguagem universal, que transcenda a questão da fronteira. [...] A memória é uma questão que me interessa muito, porque acho que, para pensarmos o futuro, temos que fazer uma reflexão do passado. O passado e o futuro estão ligados. É muito importante preservar a memória. Se não tivermos cuidado em preservá-la, perdemos

a las otras salas. Como en las otras salas, convertidas en atmósferas, no percibimos fronteras ni perspectivas y el espectador se ve envuelto en un mundo bello que esconde, sin embargo, una angustia existencial combativa contra los problemas y la desigualdad social. Es así que el trabajo de Sandra Cinto se conjuga político, incidiendo en la dificultad de la travesía, de la vida. Su último paisaje es un pentagrama, donde anota el espacio y el tiempo, pero también los silencios, los vacíos... desde la otra orilla". Disponível em: http://www.caam.net/es/expos/140612_sandracinto.htm com acesso em 29 de setembro de 2014. referências e isso não é bom. Tenho realizado vários trabalhos sobre essa questão, a vontade de resgatar ou restaurar uma memória, um tempo perdido, fazer um comentário sobre situações do passado, que influenciam o presente e irão influenciar o futuro. (CINTO, IN: CANTON, 2009, p. 50-51)

A artista não trabalha sozinha, tem duas assistentes brasileiras que viajam com ela, mas algumas pessoas dos espaços onde ela expõe também acabam por ajudar no desenho das miIhares de linhas que compõesm suas paisagens. Esta é uma questão importante na poética da artista, o projeto em Seattle levou duas semanas para ser montado, sendo que ela contou com a ajuda de vários assistentes e voluntários para desenhar as linhas na parede, o que estabelece um contraponto à velocidade do tempo contemporâneo (ver figura 9). Segundo a própria artista, o tempo que eles usam para executar o projeto é um tempo suspenso, como se estivessem em uma bolha, onde o mundo exterior não existe, talvez em uma metáfora a estar em um barco, onde só a realidade presente é que importa, onde pode-se pensar que estar neste barco é um tempo suspenso. Também na instalação dos instrumentos musicais a questão está presente. Ela é enfatizada no momento em que a artista insere as pautas musicais: o lugar onde se anota o tempo da música. E sobre o processo de desenhar, ela diz que só o que define quando o desenho está pronto é a data de abertura da exposição, pois não fosse este limite temporal, ela ficava lá, desenhando com uma caneta fininha, acrescentando linhas e ondas?.

Os desenhos, feitos com caneta permanente na parede, são realizados no local, possuem um caráter efêmero e atemporal. Demandam dias,

9 Em entrevista disponível em: https://www.youtube.com/ watch?v=DQyZARscYAk, com acesso em 30 setembro de 2014. 
semanas, num processo de imersão, silêncio, resistência e cooperação entre os voluntários que se dedicam a ajudar nas milhares de linhas, junto às assistentes que acompanham a artista em suas exposições. Marisa C. Sánchez, Curadora Associada de Arte Moderna e Contemporânea do SAM e curadora deste projeto, diz: "A água cura e nutre, mas também consome e destrói. Estar em frente a instalação gigantesca de Sandra Cinto nos faz lembrar dessas qualidades que se opõem: agua como renovação e destruição. Os desenhos de Cinto são fascinantes. Revelam sua crença no poder da arte para transformar vidas cotidianas"10. Para a artista, quando alguém se vê diante de uma paisagem, a exemplo destas que ela apresenta, percebe o quanto somos pequenos frente à natureza. E no momento em que pode fazer estas ondas gigantescas na parede do pavilhão do museu, ela é capaz de colocar o espectador entre a paisagem ideal e a paisagem 'real', que é a paisagem externa do pavilhão, visível através das portas de vidro. Ao mesmo tempo em que ela 'mergulha' seu espectador na fantasia criada pelas linhas de caneta permanente na parede, 'água real, água imaginária, água-arte, podemos dizer”, cita a artista ${ }^{11}$.

\section{Referências:}

CANTON, Katia. Tempo e memória. Temas da arte contemporânea. SP: Martins Fontes, 2009.

LEWITT, S. (1967). Paragraphs in Conceptual Art. In: Artforum 5, no. 10, pp. 79-83, June 1967. http://www.caam.net/es/140612scinto_v.htm http://arte1.band.uol.com.br/paisagem-silenciosa/

http://arteref.com/instalacao/mural-de-san- dra-cinto-no-seattle-art-museum/

http://www.caam.net/es/140612scinto_v.htm

http://arteref.com/instalacao/mural-de-sandra-cinto-no-seattle-art-museum/

http://www.casatriangulo.com/pt/news/ $\operatorname{tag} / 90 /$

10 Disponível em: http://www.casatriangulo.com/pt/news/ tag/90/

11 Em entrevista disponível em: http://arteref.com/instalacao/mural-de-sandra-cinto-no-seattle-art-museum/, com acesso em 30 de setembro de 2014. 
